\title{
Bacterial Translocation as a Cause of Postoperative Sepsis in Surgical Patients Undergoing Laparotomy
}

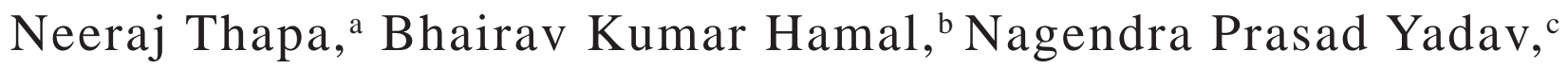 \\ Ghanshaym Thapa ${ }^{\mathrm{d}}$
}

\begin{abstract}
:
Introduction: Bacterial translocation is the invasion of indigenous intestinal bacteria through the gut mucosa to normally sterile tissues and the internal organs. Objective of the study is to examine the spectrum of bacteria involved in translocation in surgical patients undergoing laparotomy and to determine the relation between nodal migration of bacteria and the development of postoperative septic complications. Methods: Mesenteric lymph nodes (MLN) culture was done in patients undergoing elective and emergency surgeries fulfilling the inclusion criteria. Results: Bacterial translocation was identified in $22(44.8 \%)$ patients. The most common organism identified was Escherichia coli $(n=11,50 \%)$. Both enteric bacteria, typical of indigenous intestinal flora, and non-enteric bacteria were isolated. Postoperative septic complications developed in four (11\%) patients. Septic morbidity was more frequent when a greater diversity of bacteria resided within the mesenteric lymph nodes. Conclusion: Bacterial translocation is associated with an increase in the development of postoperative sepsis in surgical patients. The organisms responsible for septic morbidity are similar in spectrum to those observed in the mesenteric lymph nodes. These data strongly support the gut origin hypothesis of sepsis in humans. Besides, there is increased bacterial translocation in patients undergoing emergency procedures.
\end{abstract}

Keywords: bacteria $\bullet$ laparotomy $\bullet$ postoperative $\bullet$ sepsis $\bullet$ translocation

\section{INTRODUCTION:}

Bacterial translocation is defined as the passage of viable bacteria from the gastrointestinal (GI) tract through the mucosal epithelium to other sites, such as the mesenteric lymph nodes, spleen, liver and blood. ${ }^{1}$ This term also applies to the passage of inert particles and other macromolecules, such as lipopolysaccharide endotoxins across the intestinal mucosal barrier.

\section{a - Lecturer, Department of Surgery}

Lumbini Medical College Teaching Hospital, Palpa, Nepal

b - Professor and Head, Department of Surgery

Shree Birendra Chhauni Hospital, Kathmandu, Nepal

c - Surgeon, Janakpur Zonal Hospital, Nepal

d - Assistant Professor, NAMS, Bir Hospital, Kathmandu, Nepal

Corresponding Author:

Dr. Neeraj Thapa

e-mail: drneerajthapa@gmail.com

\section{How to cite this article:}

Thapa N, Hamal BK, Yadav NP, Thapa G. Bacterial translocation as a cause of postoperative sepsis in surgical patients undergoing laparotomy. Journal of Lumbini Medical College. 2014;2(2):28-30. doi: $10.22502 / \mathrm{jlmc} . v 2 \mathrm{i} 2.53$.
In recent years 'gut barrier function' has been increasingly recognized which means the gut is also a metabolic and immunological organ that serves as a barrier against living organisms and antigens within its lumen. The fact that luminal contents in the caecum have a bacterial concentration of the order of $10^{12}$ organisms per $\mathrm{ml}$ of faeces, while portal blood and mesenteric lymph nodes are usually sterile, dramatically illustrates the efficacy of this barrier function. ${ }^{2}$ The idea that the alimentary tract, teeming with its own bacterial flora, could represent a source of sepsis referred as 'gut origin of sepsis' under certain conditions has interested clinicians for many years. Many studies have been done and subsequently it has become clear that, in addition to gram-negative bacteria, endotoxin, gram-positive bacteria and fungi can pass through the mucosal barrier. $^{3-7}$ Subsequently it has become clear that, in addition to Gram-negative bacteria, endotoxin, Gram-positive bacteria and fungi can pass through the mucosal barrier which has been termed as 'bacterial translocation'.8

There is no doubt that bacterial translocation occurs in humans. ${ }^{9}$ It has a prevalence of about 
$15 \%$ in elective surgical patients and occurs more frequently in patients with intestinal obstruction and those who are immunocompromised. ${ }^{9-11}$ Many studies have established an association between gastrointestinal microflora and nosocomial infection supporting the concept of the gut as reservoir of bacteria and endotoxins. ${ }^{12,13}$ With increasing severity of illness, bacterial translocation occurs because of the inability of the host to deal adequately with the numbers of bacteria present. ${ }^{14}$

Bacterial translocation occurs commonly to mesenteric lymph nodes so the culture of the same gives a valuable idea regarding the organisms responsible for sepsis. The purpose of our research was to observe the relationship between the bacterial translocation and the development of postoperative sepsis along with the observation of spectrum of organisms identified within the mesenteric lymph node culture and the rate of bacterial translocation depending upon the laparotomy done as elective or emergency basis.

\section{METHODS:}

A prospective observational study was conducted between June 2011 and May 2012 at General Surgery clinic and Emergency Department of Bir hospital and Patan Hospital following approval from the ethical review committee of the institutes. Patients with preoperative sepsis and co-morbidities were excluded from the study. Patients undergoing elective and emergemcy laparotomy were included in the study. Surgery was performed by either consultants or registrars. Perioperatively, enloarged mesenteric lymph nodes were excised with a sterile surgical blade and transported in seperate sterile containers with normal saline and sent for aerobic and anaerobic cultures. Aerobic culture was done in blood agar at $37^{\circ} \mathrm{C}$ and reports were interpreted from third to fifth day. Anaerobic culture was done in Robertsons cooked meat media at $37^{\circ} \mathrm{C}$. The report of anerobic culture was obtained at 5-7 days.

The data was entered in Microsoft Excel and statistical analysis was done using SPSS (Statistical package for social studies) version-13 software. Various statistical tests were used and a 95\% confidence interval and $P<.05$ were considered as statistically significant.

\section{RESULTS:}

In our study 49 patients were included out of which $26(53.1 \%)$ were males and $23(46.9 \%)$ were females. Chi-square "goodness of fit" test was applied which showed that the difference was not statistically significant, $X^{2}(N=49)=.08, p=.78$. Both elective and emergency procedures were included.
There were $41(83.67 \%)$ of emergency and only 8 $(16.33 \%)$ of elective procedures. Mean age of patients was 41.94 years $(S D=15.59)$. Most common $(71.4 \%)$ diagnosis in our study was peritonitis (Table 1). Mesenteric lymph node cultures were done to detect the bacterial translocation. Culture was positive in 22 $(45 \%)$ of the samples. The most common organisms cultured were Escherichia coli 11 (22.4\%) followed

Table 1: Frequency distribution of diagnosis.

\begin{tabular}{llc}
\hline SNo. & Diagnosis & $N(\%)$ \\
\hline 1 & Peritonitis & $35(71)$ \\
2 & Cholelithiasis & $6(12)$ \\
3 & Colon carcinoma & $4(8)$ \\
4 & Gastric carcinoma & $2(4)$ \\
5 & Pancreatic carcinoma & $1(2)$ \\
6 & Carcinoma gallbladder & $1(2)$ \\
\hline
\end{tabular}

by Proteus $5(10.2 \%)$, Bacteroides $3(6 \%)$ and Staphylococcus aureus $3(6 \%)$. E. coli was found to be highest in age group of 41-60 years. Culture was positive most frequently $(n=16)$ in patients with peritonitis. Bacterial translocation increased with age, mostly after 40 years; $16.33 \%$ of it was seen in the age group 41-50yrs. Translocation of bacteria was more common (52\%) in emergency cases as compared to elective cases $(11 \%)$. Postoperative sepsis was noted in $8 \%$ of patients who had bacterial translocation and this was statistically significant (Table 2).

\section{DISCUSSION:}

Those patients who had positive mesenteric lymph node culture had bacterial translocation and those with bacterial translocation developed sepsis in a few cases. Not all patients with bacterial

Table 2: Relation between Bacterial translocation and Postoperative sepsis

\begin{tabular}{lcccc}
\hline & \multicolumn{4}{c}{ Post-op sepsis } \\
& \multicolumn{5}{c}{ Yes } & No \\
\hline Bacterial & Yes & 4 & 18 & $F=5.35$ \\
translocation & No & 0 & 27 & $p=.02$ \\
\hline
\end{tabular}

translocation developed sepsis but few of them who had decreased immunity owing to old age and emergent cases developed sepsis in our study.

In a study conducted by Macfie et al. which included 927 patients, age group ranged from 6077 years and the male to female ratio was similar to our study. There were more elective cases (80\%). The most common diagnosis in their study was malignancy which consisted of $58.57 \%$ of total cases 
which is unlike in our study. Along with mesenteric lymph node culture nasogastric aspirates were sent for culture, which was not included in our study. The most common enteric organisms to be cultured in their study were E. coli (20\%), Lactobacillus spp. (14\%), Enterococcus spp. (12\%), and Enterobacter spp. (9\%). The genus Enterobacteriaecae (enteric gram negative facultative anaerobic rods) which includes E. coli and Enterobacter species was present in $35 \%$ of positive cultures, which is similar to our study. Postoperative sepsis was common in those with bacterial translocation $(42.3 \%)$ which was similar to our study. ${ }^{14}$ Their study period was 13 years unlike ours, which included only laparotomies done within a year.

In another study conducted by Boyle, 448 patients were included with median age of 67 yrs. Bacterial translocation occurred in $15.4 \%$ of patients in their study, whereas in our study bacterial translocation occurred in $44.8 \%$ of patients. The presence of distal intestinal obstruction at laparotomy was the strongest predictor of translocation and occurred in $41 \%$ of patients. Age greater than 70 years and the necessity for urgent surgery were also associated with significantly increased translocation rates (both $21 \%$ ) in their study. The most common organism cultured was E. coli (54\%), which was the same in our study (22.4\%). Forty one percent of patients who had evidence of bacterial translocation developed sepsis compared with $14 \%$ of patients in whom no organisms were cultured. ${ }^{9}$ In our study $8 \%$ of patients who had evidence of bacterial translocation developed sepsis.

A study in neonates defined microbial translocation as having occurred if organisms isolated from blood samples were also carried in the throat or rectum. They reported six infants with 15 episodes of septicaemia attributable to enteric organisms. ${ }^{15}$

Availability of laboratories round the clock would have been an important factor and particularly in our study where most of the emergency cases were included. But it was not feasible in our study as culture was done during the working hours only. Mesenteric culture is an important indicator of bacterial translocation and was employed in our studies but in other studies nasogastric aspirates have also been used. Mesenteric lymph node culture gives a precise idea of organisms involving in sepsis. Limitations of our study were small number of cases and a short duration of study. Use of limited variables related to bacterial translocation which included unavailability of anaerobic culture at various times and use of only single method of mesenteric lymph node culture for the evaluation of postoperative sepsis. Not all surgeries were performed by a single surgeon and the study was not carried out in a single institute.

\section{CONCLUSIONS:}

Based on the study conducted it can be concluded that the post-operative infections tend to be more in elderly patients and emergency cases particularly related to peritonitis. All the patients with bacterial translocation don't develop sepsis but those patients who have developed sepsis have bacterial translocation indicated by positive mesenteric lymph node culture. Another important conclusion that can be made is the gut origin of sepsis indicated by the growth of organisms in mesenteric lymph node culture similar to normal gastro-intestinal flora.

\section{REFERENCES:}

1. Berg RD. Bacterial translocation from the intestines. Jikken Dobutsu. 1985 Jan;34(1):1-16.

2. Simon G. The human intestinal microflora Dig Dis Sci. 1986;31:147S-62S.

3. Fraenkel A. Ueber Peritonaele Infection. Wein Klin Wochenschr. 1891;4(241):241,65,85.

4. Flexner S. Peritonitis caused by the invasion of the Micrococcus lanceolatus from the intestine. John Hopkins Hosp Bull. 1895;6:64-7

5. Schweinburg F, Frank H, Frank E, Heimberg F, Fine J. Transmural migration of intestinal bacteria during peritoneal irrigation in uremic dogs. Proc Soc Exp Biol Med. 71:150-3.

6. Schatten W, Desprez J, Holden W. A bacteriologic study of portal-vein blood in man. Arch Surg. 1955;71:404-9.

7. Lemaire LC, van Lanschot JJ, Stoutenbeek CP, van Deventer SJ, Wells CL, Gouma DJ. Bacterial translocation in multiple organ failure: cause or epiphenomenon still unproven. Br J Surg. 1997 Oct;84(10):1340-50.

8. Berg R, Garlington A. Translocation of certain indigenous bacteria from the gastrointestinal tract to the mesenteric lymph nodes and other organs in the gnotobiotic mouse model. Infect Immun. 1979;23:403.

9. O'Boyle CJ, MacFie J, Mitchell CJ, Johnstone D, Sagar PM, Sedman PC. Microbiology of bacterial translocation in humans. Gut. 1998 Jan;42(1):29-35.

10. Dietch E. Simple intestinal obstruction causes bacterial translocation in man. Arch Surg. 1989;124:699-701.

11. Sagar P, MacFie J, Sedman P, May J, Mancey-Jones $\mathrm{B}$, Johnstone D. Intestinal obstruction promotes gut translocation in man. Dis Colon Rectum. 1995;38:640-4.

12. MacFie J, O'Boyle C, Mitchell CJ, Buckley PM, Johnstone D, Sudworth P. Gut origin of sepsis: a prospective study investigating associations between bacterial translocation, gastric microflora, and septic morbidity. Gut. 1999 Aug;45(2):223-8.

13. Marshall J, Christou N, Meakins J. The gastrointestinal tract:the undrained abscess of multiple organ failure. Ann Surg. 1993;218:111-9.

14. MacFie J. Current status of bacterial translocation as a cause of surgical sepsis. Br Med Bull. 2004;71:1-11.

15. Pierro A, van Saene HK, Donnell SC, Hughes J, Ewan C, Nunn AJ, et al. Microbial translocation in neonates and infants receiving long-term parenteral nutrition. Arch Surg. 1996 Feb;131(2):176-9. 